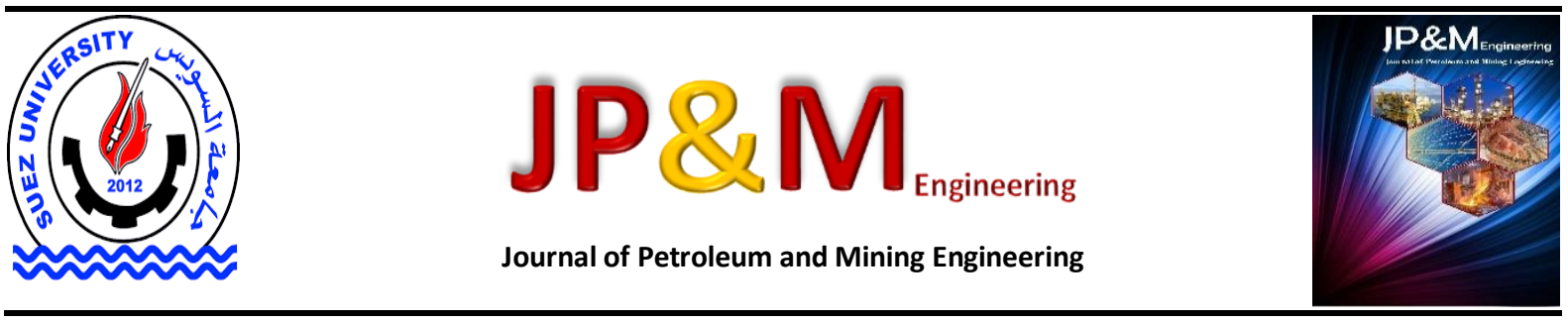

\title{
Evaluation of Physical and Geomechanical Characteristics at a Steel Rolling Factory at Ataqa industrial Zone, Suez, Egypt using Seismic Methods
}

\author{
Mesbah, M. A., ${ }^{\text {a Salama, A.M., }}{ }^{\text {b }}$ Albarqawy, M.A., ${ }^{a}$ and Ali, E. M. ${ }^{* a}$ \\ a Geological and Geophysical Engineering Department, Faculty of Petroleum and Mining Engineering, Suez University, Suez, Egypt. \\ ${ }^{b}$ National Research Institute of Astronomy and Geophysics (NRIAG), Helwan, Egypt \\ *Corresponding author e-mail: eslam.ali@suezuni.edu.eg
}

\section{Article Info \\ Received: 17 Dec. 2020 \\ Revised: 27 Jan. 2021 Accepted: 7 Feb. 2021}

\section{Keywords}

Seismic refraction; MASW; Mechanical properties; Geotechnical investigations; Bearing capacity.

\begin{abstract}
Our investigations are aimed to calculate the physical and geomechanical characteristics needed to assess the geotechnical suitability of the subsurface at Ataqa industrial zone, Suez, Egypt for constructing some industerial facilities. To accomplish our target, four seismic profiles are conducted using the refraction technique to estimate the primary seismic wave velocity as well as four profiles using the method of "Multichannel Analysis of Surface Waves" for estimating the velocity of shear waves. The stage of processing and interpretation are performed through using the "Seislmager/2D" Software. The results clarify the existence of two layers to a depth of $18 \mathrm{~m}$. The top layer ranges in thickness between 2 and $4 \mathrm{~m}$ and has a primary wave velocity ranging between 924 and $1247 \mathrm{~m} / \mathrm{s}$ and a shear wave velocity ranging between 530 and $745 \mathrm{~m} / \mathrm{s}$. On the other hand, the second layer possesses an average primary velocity ranging between 1277 and $1573 \mathrm{~m} / \mathrm{s}$ and a shear wave velocity ranging between 684 and $853 \mathrm{~m} / \mathrm{s}$. The measured velocities are utilized to calculate many physical and geomechanical properties of the earth materials comprising the two layers in our study area. The integration between all these parameters proves the suitability of both layers for erecting the proposed constructions.
\end{abstract}

\section{Introduction}

In engineering projects, the physicomechanical properties of the subsurface materials greatly affect both the construction operation and the project design. Measuring these properties is a very expensive and time-consuming process in addition to that, sometimes it becomes difficult to have samples to conduct laboratory tests to assess the conditions of the subsurface earth materials as stated by Khandelwal [1]. The relations between the seismic wave velocities of earth materials and their physicomechanical properties have been studied by many researchers such as Gaviglio [2], Boadu [3], and Khandelwal and Ranjith [4] and they clarified that rock properties are closely related to the primary and secondary wave velocities which are influenced by many factors such as the rock type and its grain size, density, porosity, and the filling fluids, temperature and confining pressure, weathering and alteration zones.

The location of the study area is situated between latitudes $29^{\circ} 55^{\prime} 37.34^{\prime \prime} \mathrm{N}$ and $29^{\circ} 55^{\prime} 41.46 \mathrm{~N}$ and longitudes $32^{\circ} 26^{\prime} 25.55^{\prime \prime} \mathrm{E}$ and $32^{\circ} 26^{\prime} 28.53^{\prime \prime} \mathrm{E}$ and extends to cover $10,652 \mathrm{~m} 2$. The refraction method is a non-destructive technique and also is considered a cost-effective geophysical method that is commonly used in various applications in many different fields such as environmental, archaeological, and hydrological investigations, the detection of voids, cracks, fractures, and fault zones, and particularly in engineering applications. Refraction and MASW techniques are frequently applied to investigate the physical and mechanical properties of the subsurface materials (e.g., Mesbah et al. [5]).

\section{Geological and structural setting}

The surface geology and some structures of the Northwestern Gulf of Suez region are shown in Fig. (2). Many authors such as Sadek [6], Said [7], and EGSMA [8] had studied the surface geology of the study area and could distinguish different rock units ranging in age from the Jurassic to Quaternary. Eocene rocks cover the northern parts of and are divided into the middle and are represented by limestone. The upper Eocene rocks consist of marl, clay and calcareous sandstone. Most of the wadis such as Wadi Hagul and Wadi El Badaa are mainly covered by the Miocene rocks which have shallow marine origin and consist of yellow calcareous sandstone. The Quaternary deposits cover the coastal plain and the margins below the surrounding mountains and consist of alluvium, wadi deposits, and sabkha and coastal sands. Oligocene, cretaceous, and Carboniferous rocks are also represented in the area but do not cover large areas. 
Faults are the main structures (Fig.2) which are of a major role while folding is of minor role Snousy et al. [11]. Northwestern-Southeastern faults are mainly of the gravity type and the most common set of faults in the area, which are characterized by relatively small dip angles.

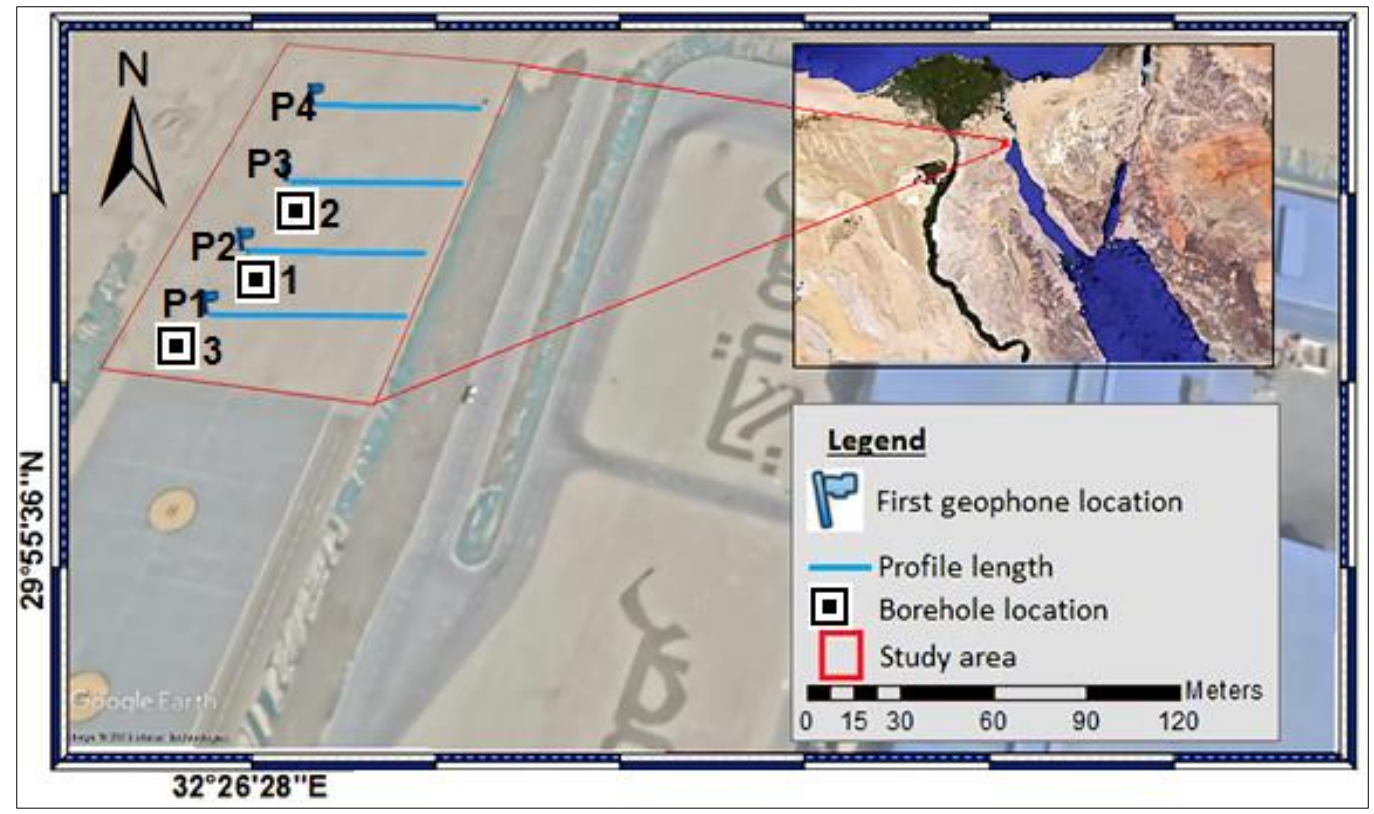

Figure 1 Location map of the study area, the layout of profiles and boreholes

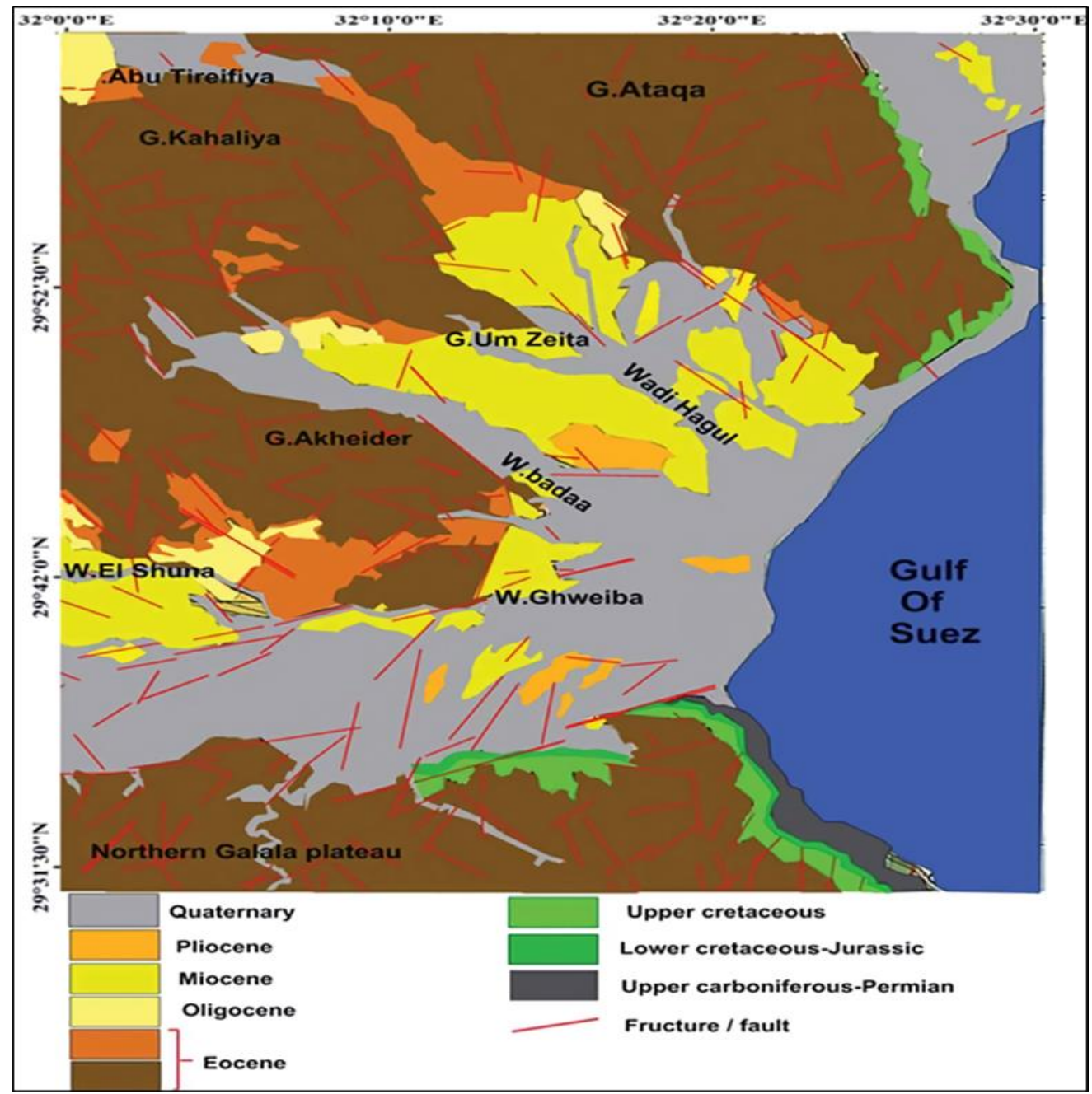

Figure 2 Geological and structural map of the study area and its surroundings Araffa et al. [9] after Conoco C. [10] 


\section{Equipments and Methods}

In this study, we are going to conduct four seismic profiles applying both refraction and MASW methods for measuring the seismic velocities. The "Time Term Inversion" technique is followed in data processing using the "Seisimager" software. The measured velocities are utilized to estimate some physical parameters such as the bulk density $(\rho)$ and porosity $(\phi)$. Different geomechanical parameters are also calculated such as the elastic moduli, the uniaxial compressive strength (UCS), ultimate tensile strength (UTS), the rippability, the SPT (N) value and the bearing capacities. The integration between all of the measured and calculated properties is used to assess the suitability of the subsurface for erecting the proposed constructions.

\section{Data acquisition}

Four seismic profiles of 55 meters in length are conducted (The layout of the profiles is shown in (Fig.1)). For generating the seismic waves, we utilize a heavy sledgehammer and a metallic plate. The data acquisition is controlled by the "24-channel SmartSeis Exploration Seismograph". In refraction profiles, three shots are carried out for every profile at an offset of $5 \mathrm{~m}$ from both ends and the middle of the profile. Four stacks are made per each shot point to increase the signal to noise ratio. We choose the sampling rate to be $0.250 \mathrm{~ms}$ and the recording length to be $500 \mathrm{~ms}$. The primary seismic waves are detected using $14 \mathrm{~Hz}$ vertical geophones. The number of geophones is 12 with a geophone interval of $5 \mathrm{~m}$.

In the MASW survey, only one shot is conducted at an offset of 15 meters from the first geophone. Five stacks are made per each shot point to enhance the signal and reduce the noise. We choose the sampling rate to be 0.500 $\mathrm{ms}$ and the recording length to be $1000 \mathrm{~ms}$. The secondary seismic waves are detected using twelve $4.5 \mathrm{~Hz}$ vertical geophones with a geophone spacing of $5 \mathrm{~m}$. We review the geotechnical investigations carried out by Albarqawy [12] to know the lithologic description of the earth materials comprising the subsurface. The description of the subsurface lithology is shown in (Fig.3).

\section{Seismic data processing and interpretation}

After collecting the seismic data from the acquisition stage, we analyze this data using the "Seislmager/2D" Software package of the latest version updated to 2020 copyright OYO company.

\section{Seismic refraction Data processing}

The acquired raw data are processed using Seislmager/2D software through the "Time-term inversion" technique. This technique is based on a combination of the linear least squares and the delay time concepts and is considered an optimum method to deduce the refractor depth and the velocity through the subsurface Wittig et al. [13]. The time-distance curves are produced by the following formula Geometrics [14] :

$$
\mathbf{t}_{\mathrm{j}}=\sum_{k=1}^{n} 2 \boldsymbol{S} j k \cos (\boldsymbol{i c}) \boldsymbol{Z} k+\boldsymbol{X} j \boldsymbol{S} 2
$$

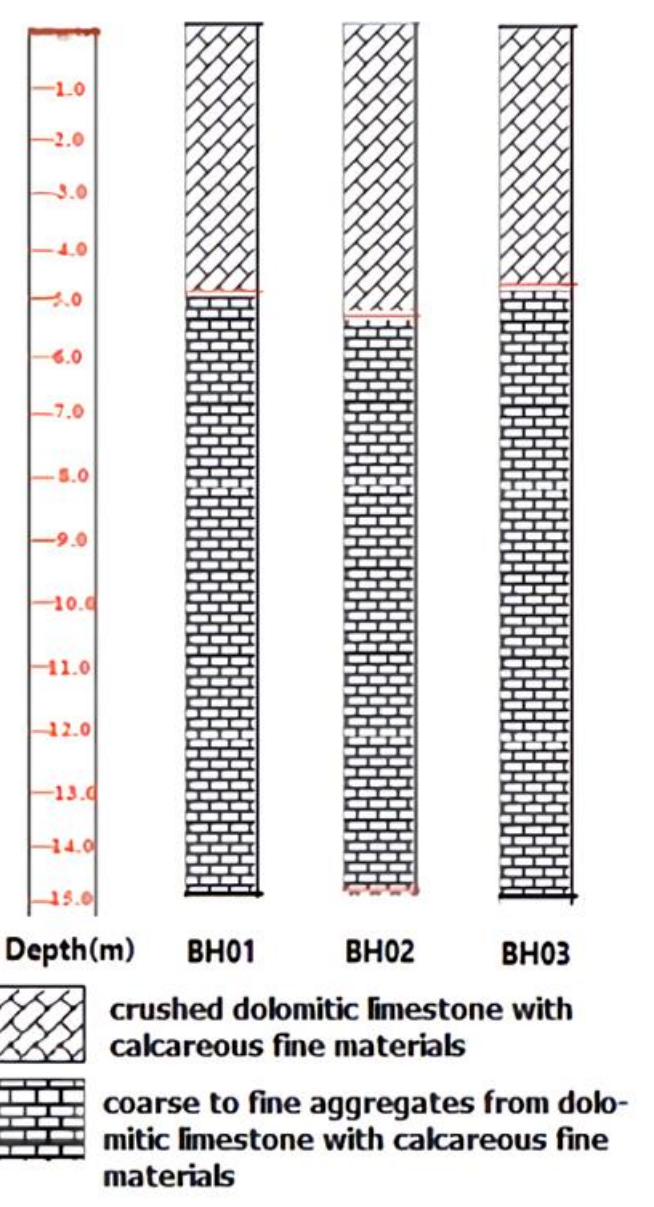

Figure 3 Subsurface lithological description as obtained from the boreholes in the study area by Albarqawy [12].

Where, $(\mathrm{tj})$ is the time taken to reach the receiver, $(\mathrm{S})$ is the "slowness" (i.e velocity inverse), $(n)$ is the sum of receivers, (ic) is the critical refraction angle, ( $\mathrm{Z}$ ) is the vertical distance to the surface of the refractor, and $(X)$ is the distance separating between the detector and the source. As an example, the time-distance curve and the corresponding velocity model of the first profile are demonstrated in Fig(4).

\section{MASW data processing}

MASW raw data are processed using the "SeisImager/SW" modules. Developing the dispersion curves is the main first step in MASW data processing Park et al. [15]. To generate the dispersion curves we select the frequency domain which ranges from 5 to $80 \mathrm{~Hz}$ in our study. After that, the following equation is utilized to generate the dispersion curve as shown in Fig(5a) Park et al. [16]:

$$
\mathrm{F}(\mathrm{c}, \omega)=\int U(x, \omega) e^{i \omega x / c} d x .
$$

Where, $F(c, \omega)$ is the phase velocity-frequency domain and $(x, \omega)$ is the distance-frequency domain. Then, the initial Vs model based on the observed data is created. The final step is the data inversion where the data is converged to find the best fit between the measured and theoretical models and eventually, we can produce the final velocity model as shown in $\mathrm{Fig}(5 \mathrm{~b})$. 


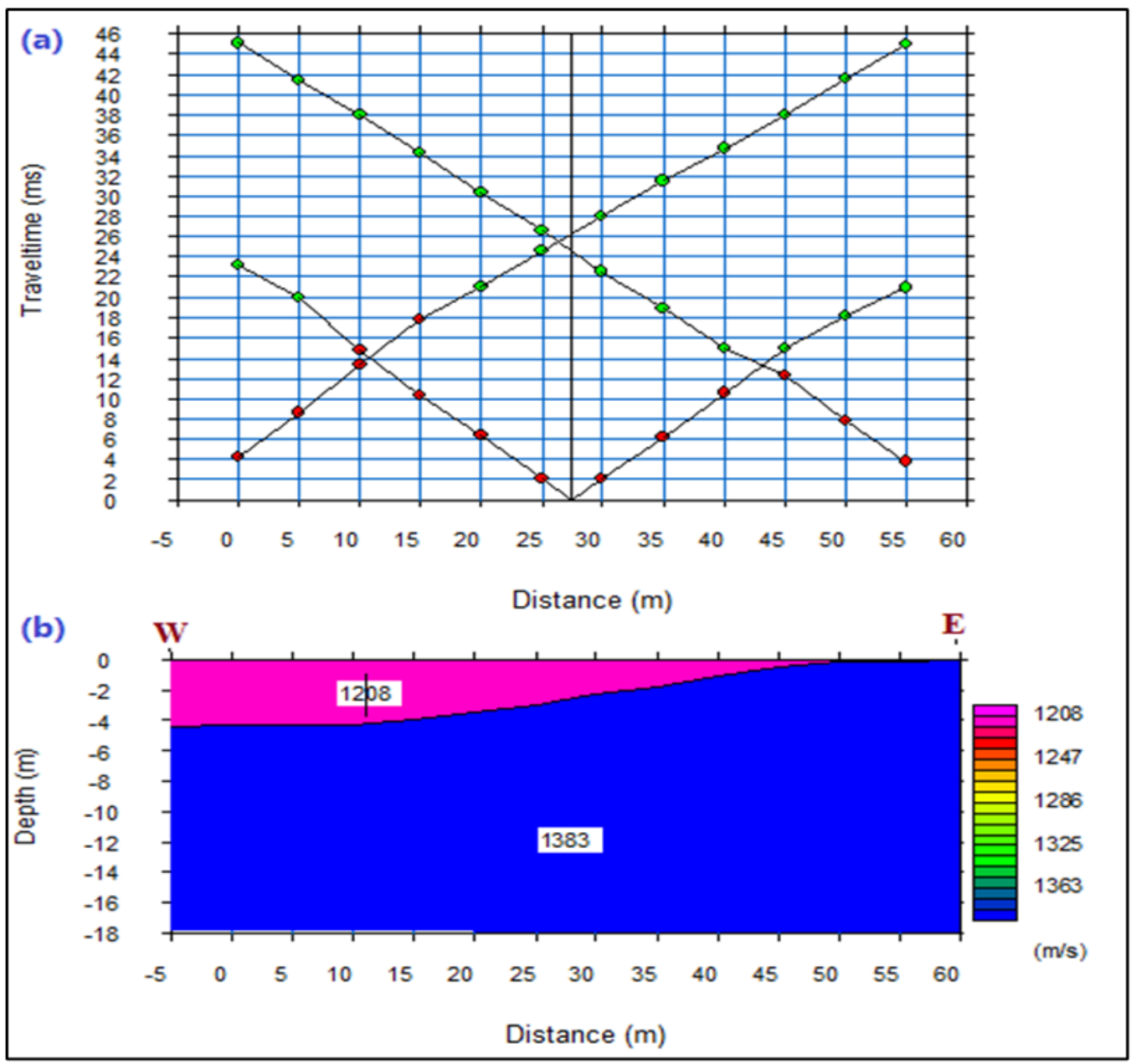

Figure 4 (a) The time-distance curve and (b) The velocity-depth model of the first profile.

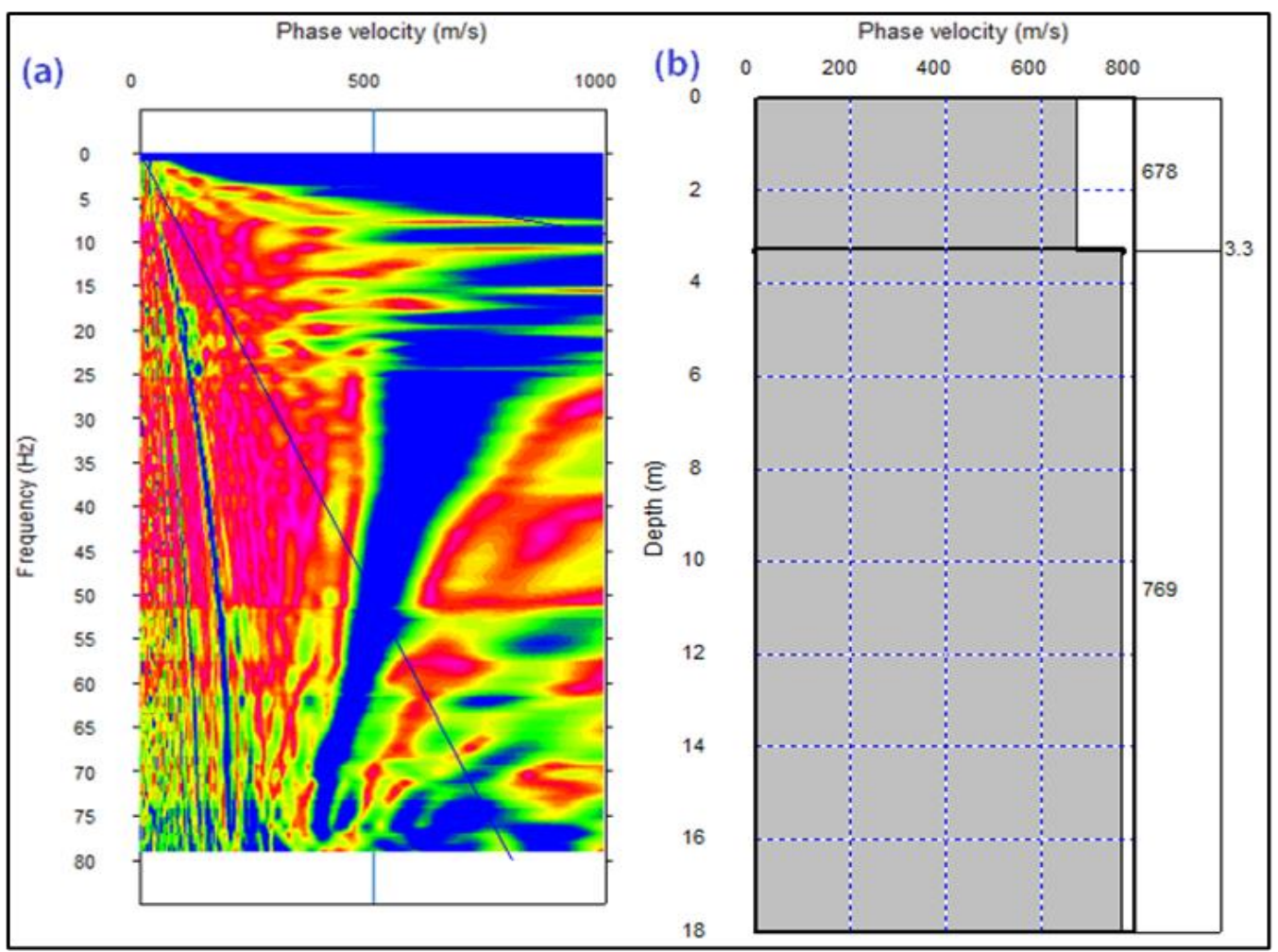

Figure 5 (a) the dispersion curve and (b) the VS model for the first profile. 


\section{Seismic data interpretation}

Results of refraction data processing have proved the presence of at least two layers to the depth of $18 \mathrm{~m}$. The first layer ranges in thickness between 2 and $4 \mathrm{~m}$ and has a primary wave velocity ranging between 924 and $1247 \mathrm{~m} / \mathrm{s}$ and a shear wave velocity ranging between 530 and 745 $\mathrm{m} / \mathrm{s}$. The contour map in Fig.(6a) shows that P-wave velocity decreases from south to north. Similarly, the contour map in Fig.(6b) shows that S-wave velocity decreases from south to north to reach the minimum value at the most northern parts. The second layer is relatively a thick layer which possesses an average primary velocity ranging between 1277 and $1573 \mathrm{~m} / \mathrm{s}$ and a shear wave velocity ranging between 684 and $853 \mathrm{~m} / \mathrm{s}$. The contour map in Fig.(7a) shows that P-wave velocity is maximum at the central part and decreases to the northern parts where it reaches its minimum value. The contour map in Fig.(7b) shows that S-wave velocity has a similar distribution pattern of P-wave in the layer.

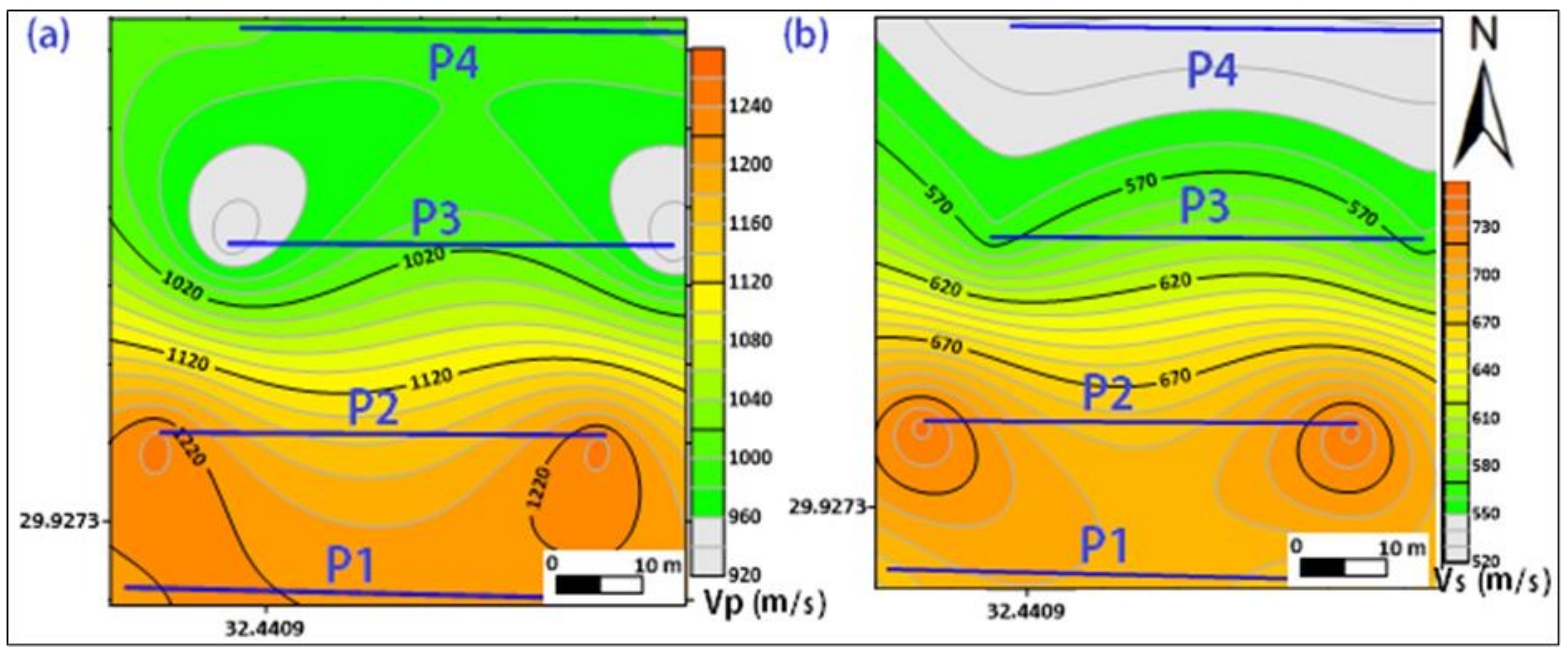

Figure 6 (a) P-wave velocity contour map of the first layer. (b) S-wave velocity contour map of the first layer.

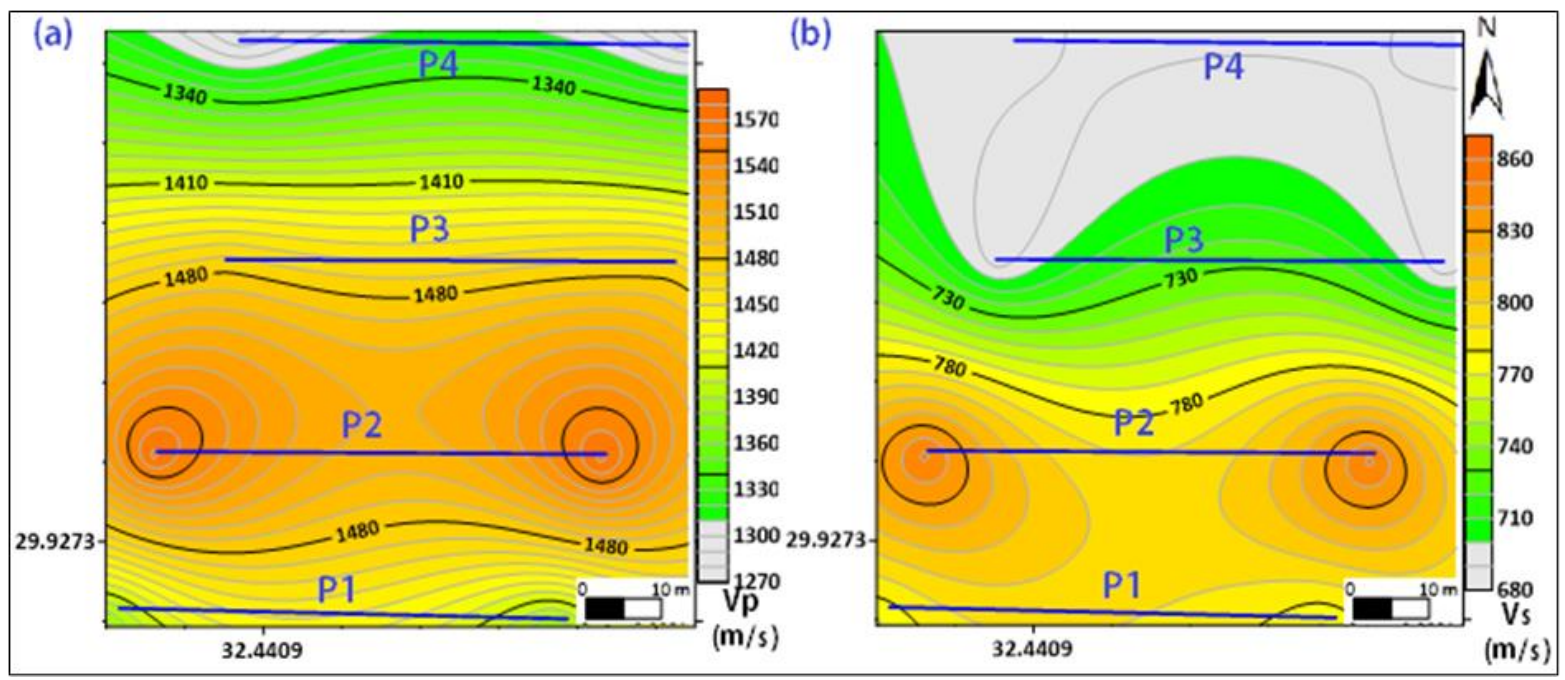

Figure 7 (a) P-wave velocity contour map of the second layer. (b): S-wave velocity contour map of the second layer.

\section{Evaluation of Physical and geomechanical characteristics}

Good understanding of the subsurface earth materials conditions is a fatal demand to make the best decisions about the designs to any of the proposed structures.

\section{Physical and Petrophysical parameters}

Bowles [17] described the subsurface materials as the most complex building materials which have higher changeable petrophysical characteristics and they have strong variations in vertical and lateral directions. To evaluate the suitability of the subsurface materials for construction, some parameters were calculated such as bulk density and porosity.

\section{Bulk density}

One of the most applied relations is the equation stated by Gardner et al. [18]:

$$
\rho=a^{*} V p^{0.25}
$$

where: $\rho$ is the bulk density in $\mathrm{g} / \mathrm{cm} 3, \mathrm{VP}$ is the primary wave velocity and (a) is a constant equal to 0.31 . The bulk density values for the first layer range from $1.71 \mathrm{gm} / \mathrm{cm} 3$ 
to $1.84 \mathrm{gm} / \mathrm{cm} 3$ (Fig.8a). The second layer possesses a bulk density ranging from $1.85 \mathrm{gm} / \mathrm{cm} 3$ to $1.95 \mathrm{gm} / \mathrm{cm} 3$ (Fig.8b).

\section{Porosity}

$$
\phi=-0.175 \ln \left(\mathrm{V}_{\mathrm{P}}\right)+1.56
$$

Where $(\phi)$ is the rock porosity and (VP) is the primary wave velocity of the rock. In this study, The first layer records

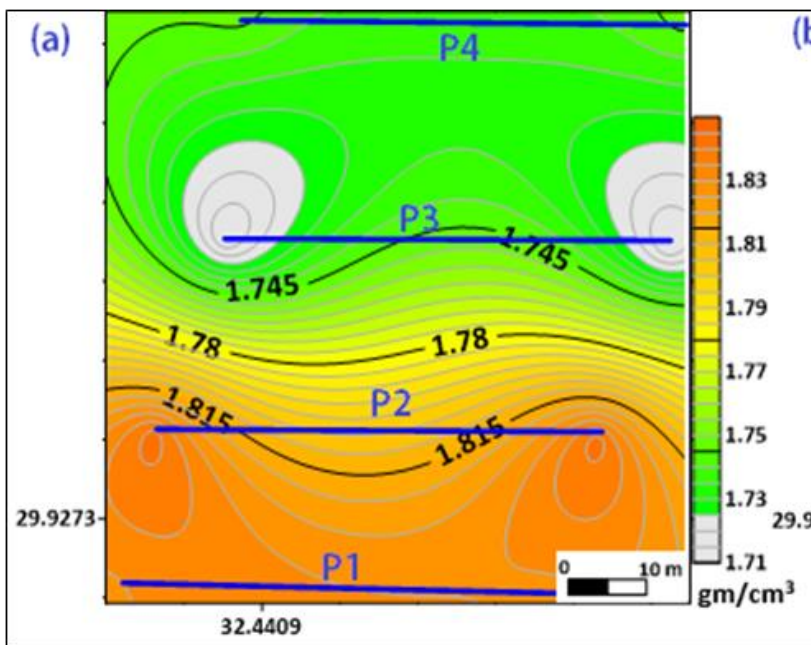

Wyllie et al. [19] studied the relationship between the compressional wave velocity through the earth materials and the porosity of these materials. They clarified that porosity greatly affects the compressional wave velocities. In our investigations we depend on the equation stated by Watkins et al. [20]:

porosity values ranging from $31 \%$ to $36 \%$ which reflects moderate porosity. On the other hand, porosity ranges in the second layer from $27 \%$ to $31 \%$ which reflects moderate to slightly low porosity materials.

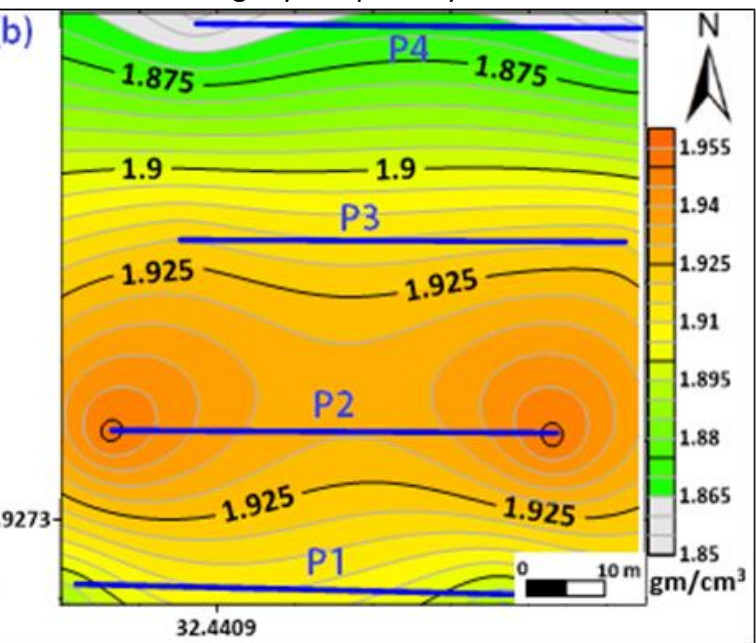

Figure 8 The bulk density contour map of: (a) the first layer and (b): the second layer.
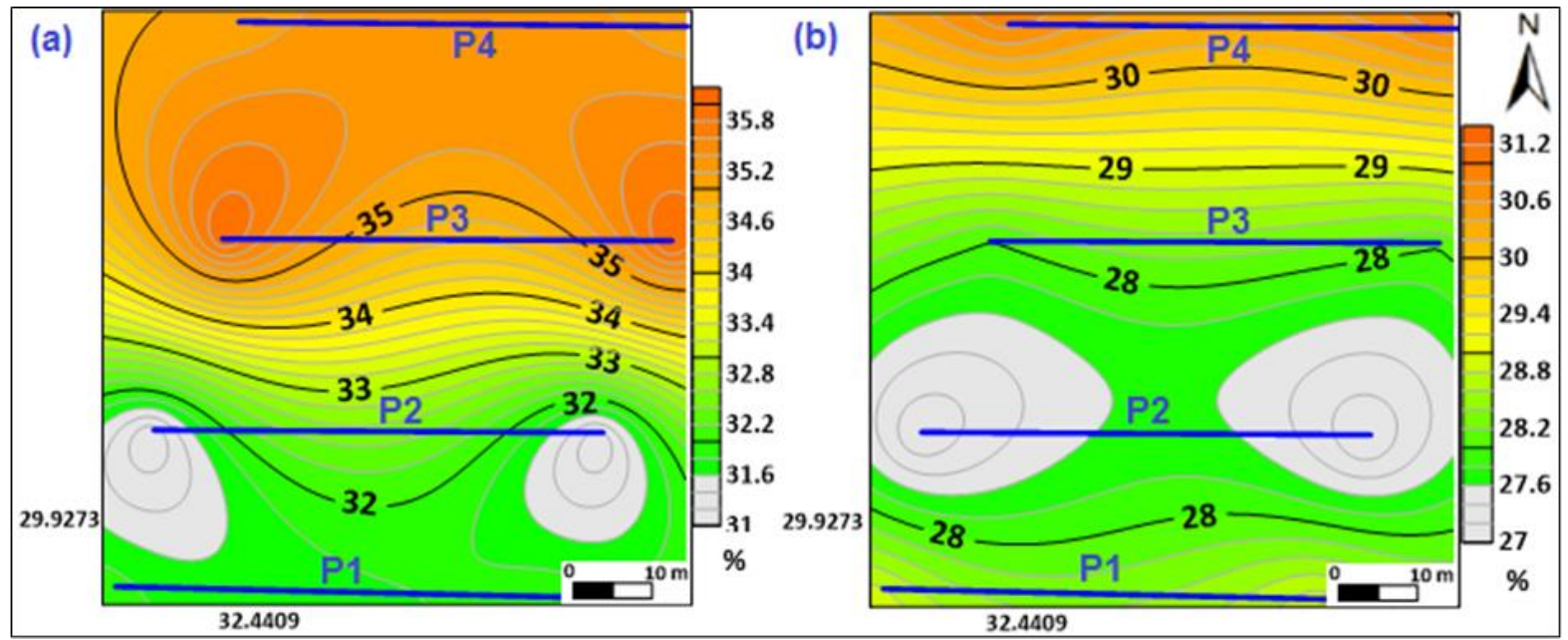

Figure 9 Porosity contour map of (a) the first layer and (b) the second layer

\section{Geomechanical parameters}

Mechanical properties of the subsurface greatly affect both the construction operation and the project design so it is important to measure and evaluate these parameters. In this study, we calculate uniaxial compressive strength and ultimate tensile strength of the subsurface.

\section{Uniaxial Compressive Strength (UCS)}

Altindag [21] developed a power relationship between UCS and VP for sedimentary rocks as follows :

$U C S=12.743 V_{P}^{1.194}$
The uniaxial compressive strength ranges from 11.6 $\mathrm{MPa}$ to $16.4 \mathrm{MPa}$ in the first layer which reflects fair to good competent rock. The second layer demonstrates uniaxial compressive strength values ranging from $17 \mathrm{MPa}$ to $21.8 \mathrm{MPa}$ which indicates good competent rock. The lateral distribution of UCS is demonstrated in Fig.(10).

\section{Ultimate Tensile Strength (UTS)}

The relationship between UTS and $V p$ can be expressed by the power equation which was stated by Altindag [21] with a regression coefficient of (0.77):

UTS $=1.0562 \mathrm{Vp}^{1.1222}$ 
In this study, The ultimate tensile strength from 0.96 $\mathrm{MPa}$ to $1.36 \mathrm{MPa}$ in the first layer which reflects fair to good competent materials. On the other hand, the second layer demonstrates ultimate tensile strength values ranging from $1.38 \mathrm{MPa}$ to $1.76 \mathrm{MPa}$ which reveals good competent rock. The lateral distribution of UTS is demonstrated in Fig.(11).

\section{Elastic Properties}

The mechanical properties of earth materials greatly depend on their elastic properties Saad et al. [22] We calculated many elastic moduli as follows.

\section{Poisson's ratio (o')}

It is a matter of fact that competent earth materials possess lower values of Poisson's ratio than incompetent materials. We calculate Poisson's ratio (o') through the application of the following equation stated by Sjögren [23]:

$$
\sigma^{\prime}=\frac{(\mathrm{Vp} / \mathrm{Vs})^{2}-2}{2(\mathrm{Vp} / \mathrm{Vs})^{2}-2}
$$

Bowles [17] distinguished four main categories of earth materials based on the values of Poisson's ratio.
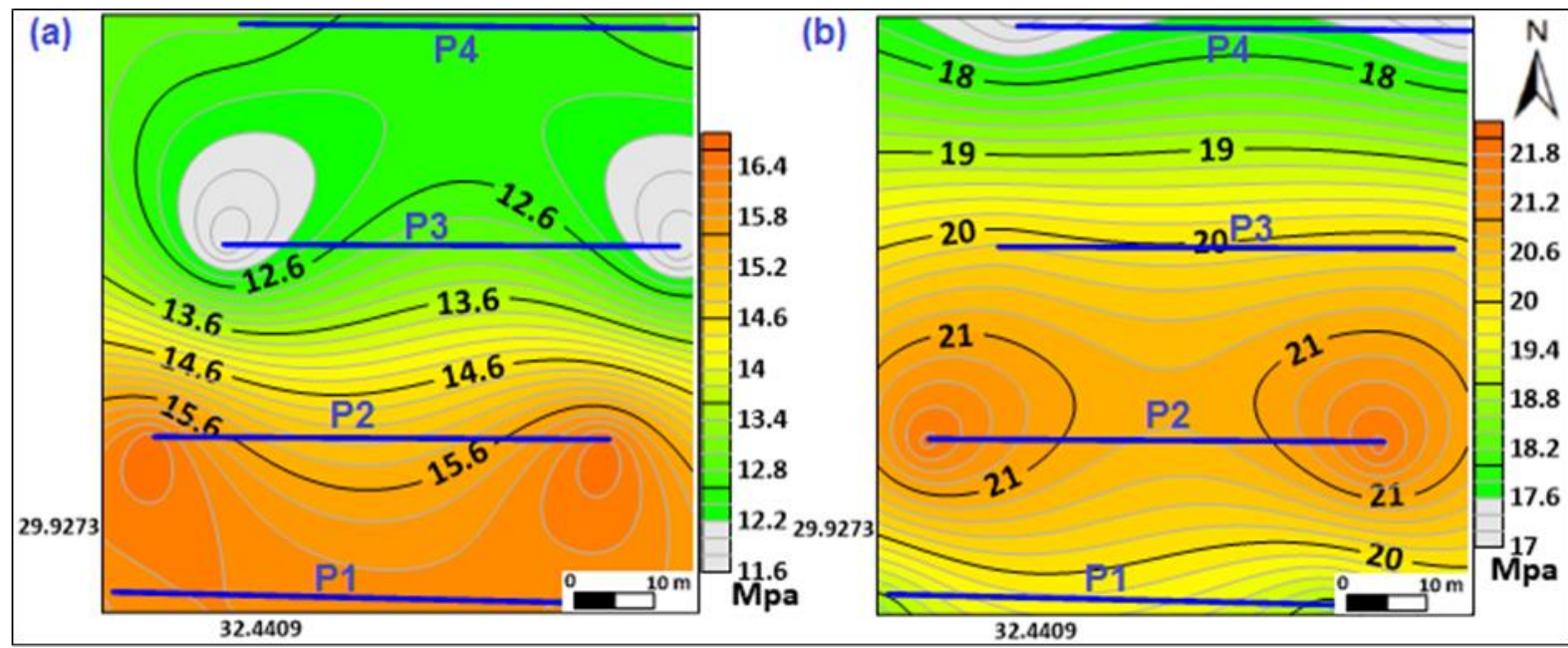

Figure 10 Uniaxial compressive strength contour map of (a) the first layer and (b) the second layer.

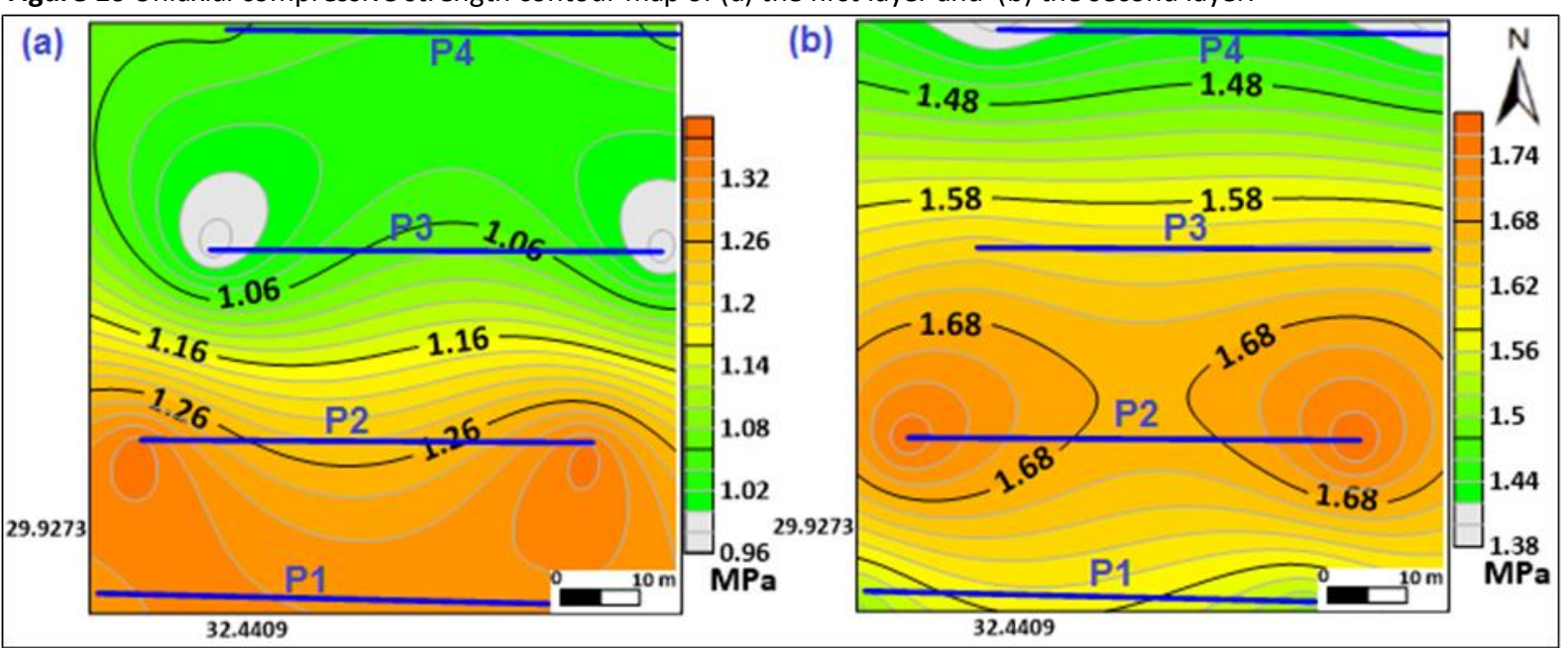

Figure 11 Ultimate Tensile Strength contour map of (a) the first layer and (b) the second layer.

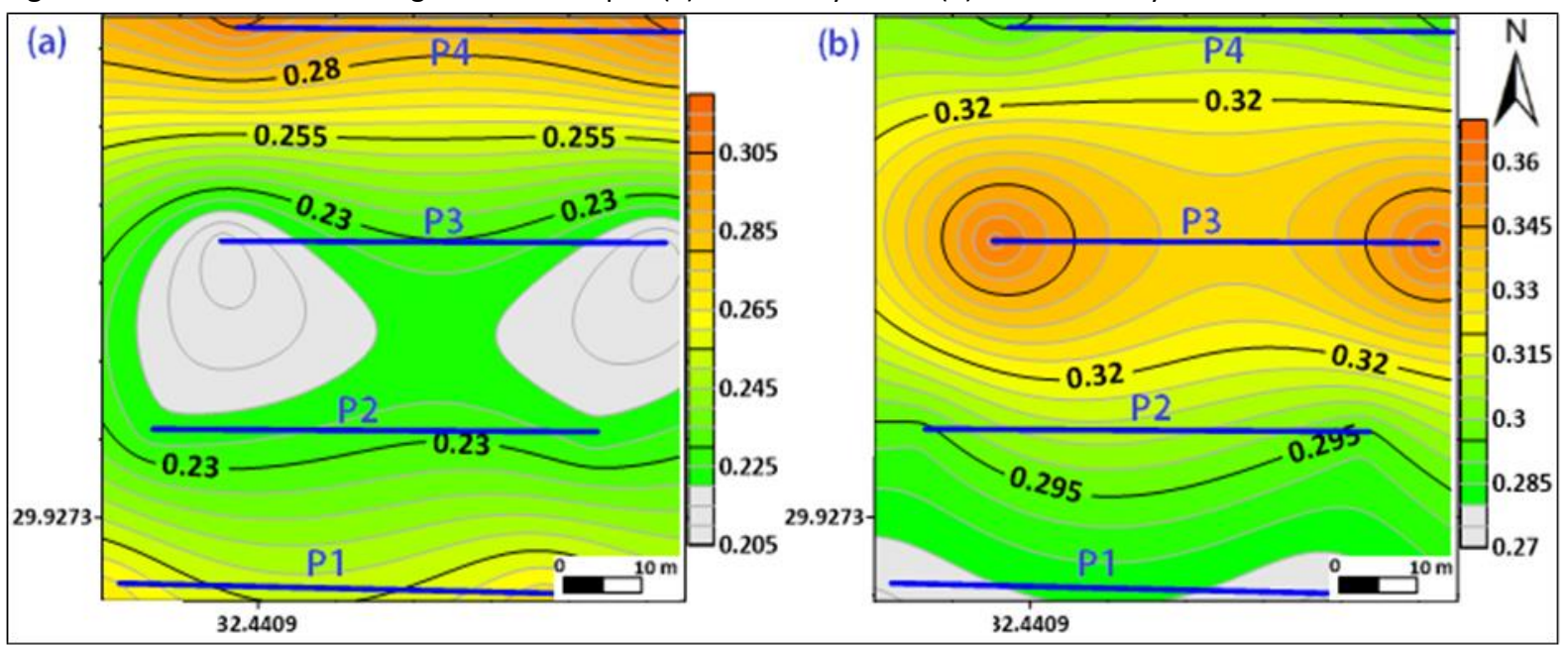

Figure 12 Poisson's ratio contour map of (a) the first layer and (b) the second layer. 
Table 1 Earth materials description concerning Poisson's ratio Bowles [17].

\begin{tabular}{|c|c|c|c|c|}
\hline Description & $\begin{array}{c}\text { Incompetent to slightly } \\
\text { competent }\end{array}$ & $\begin{array}{c}\text { Fairly to moderately } \\
\text { competent }\end{array}$ & Competent materials & Very high competent \\
\hline $\begin{array}{c}\text { Poisson's } \\
\text { Ratio }\end{array}$ & $0.41-0.49$ & $0.35-0.27$ & $0.25-0.16$ & $0.12-0.03$ \\
\hline
\end{tabular}

The Poisson's ratio of the first layer ranges between 0.21 and 0.31 . We can classify the central parts as competent materials and other parts as fairly to moderately competent properties. Poisson's ratio ( $\left.\sigma^{\prime}\right)$ in the second layer ranges from 0.27 to 0.36 reflecting fairly to moderately competent materials.

\section{Shear modulus $(\mu)$.}

Toksöz et al. [24] measured the shear modulus in terms of shear wave velocity (VS), density ( $\rho$ ) as follows:

$\mu=\rho * v^{2}$

(8).

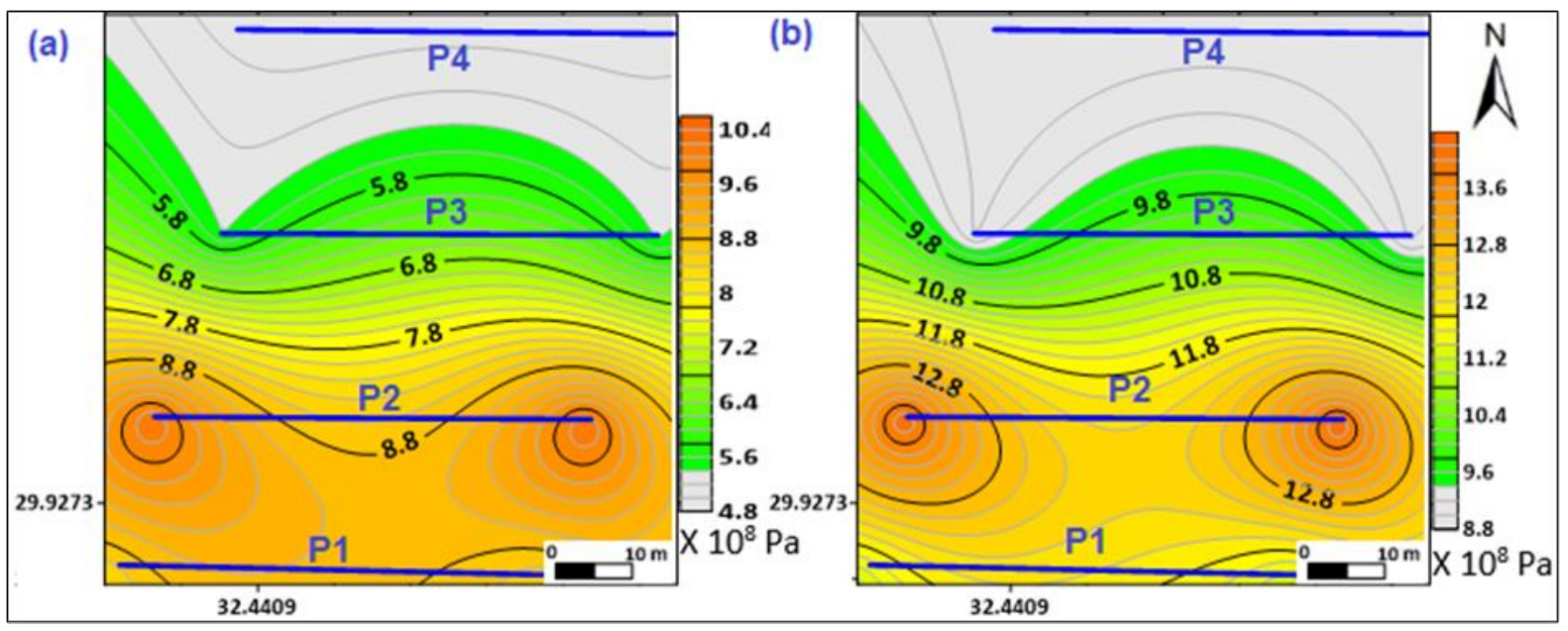

Figure 13 The shear modulus contour map of (a) the first layer and (b) the second layer.

\section{Young's modulus (E)}

Young's modulus can be calculated using the following equation stated by Lowrie [25]:

$$
E=2 \mu\left(1+\sigma^{\prime}\right)
$$
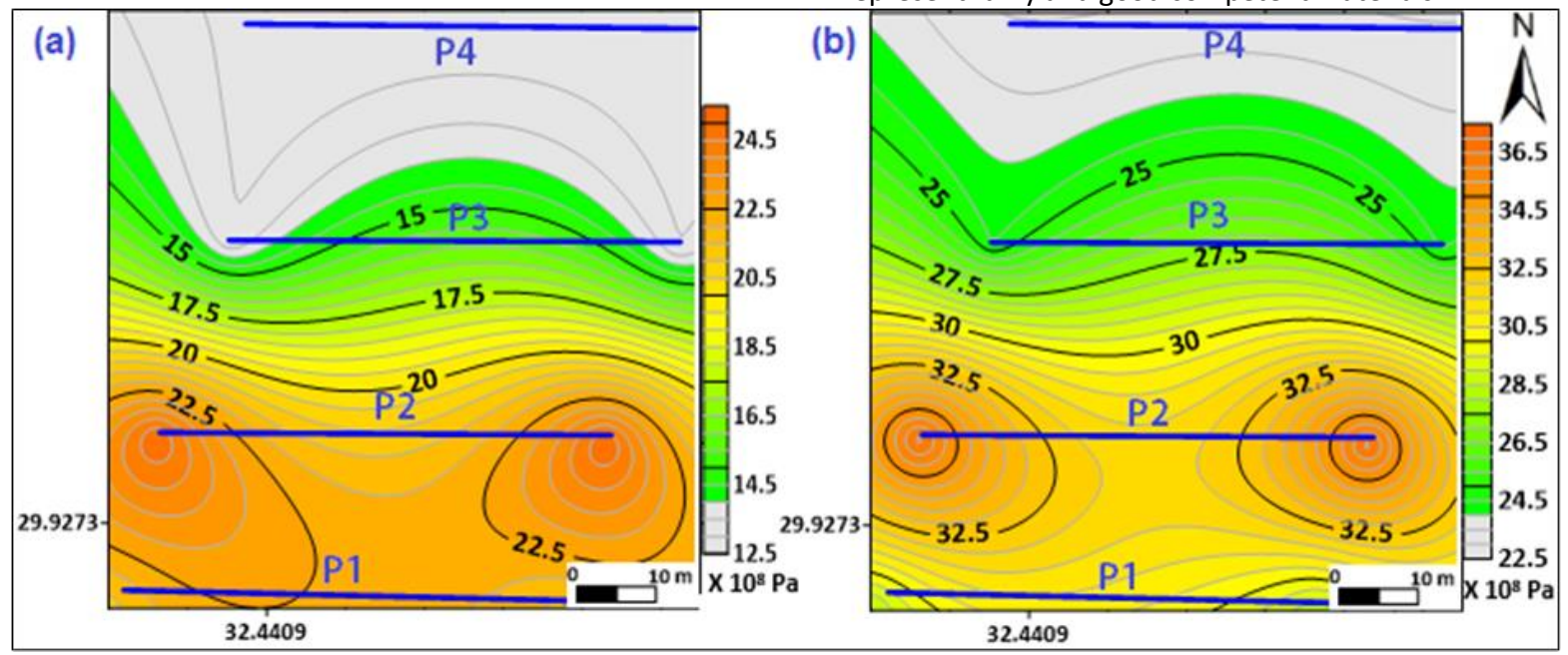

Young's modulus demonstrates values ranging between 1.29 and 2.50GPa within the first layer, whereas the second layer has values ranging between 2.30 and $2.85 \mathrm{GPa}$. The values of Young's modulus in both layers represent fairly and good competent materials.

Figure 14 Young modulus contour map of (a) the first layer and (b) the second layer. 


\section{Bulk modulus (K)}

Bulk's modulus can be calculated using the following equation stated by Lowrie [25]:

$K=E / 3\left(1-2 \sigma^{\prime}\right)$

Bulk's modulus demonstrates ranges between 0.74 and $1.55 \mathrm{GPa}$ representing fairly competent materials in the first layer, while Bulk's modulus varies between 1.84 and 2.97GPa representing good competent materials in the second layer.

\section{Rippability}

A very well-known application of the primary wave velocity is the estimation of rippability - the ease with which the ground may be drilled or excavated by machines or in other words the resistance of the material to excavation. In 1958, the Caterpillar Tractor Company developed the use of seismic velocities determined from surface refraction experiments to produce a practical chart (Fig.16) of rippability Reynolds[26] . Using this chart, contractors can estimate the ease of excavating a given area of the ground using a certain mechanical device. The estimation of rock and soil rippability using the seismic velocities had been reviewed extensively by MacGregor et al [27]. In our study, the highest primary wave velocity recorded is less than $1570 \mathrm{~m} / \mathrm{s}$ which is -according to (Fig.16)- considered rippable (i.e. can be excavated by mechanical methods and there is no need for explosives).

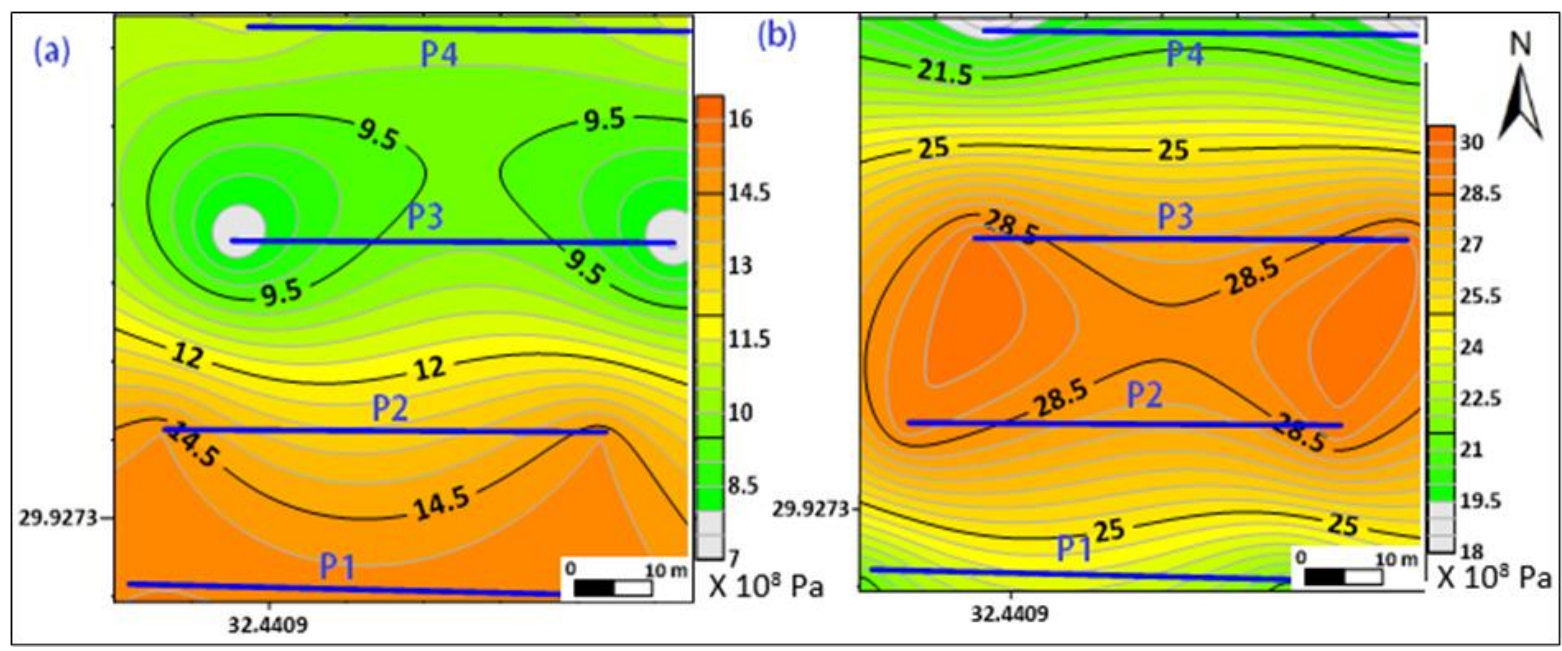

Figure 15 Bulk modulus contour map of (a) the first layer and (b) the second layer

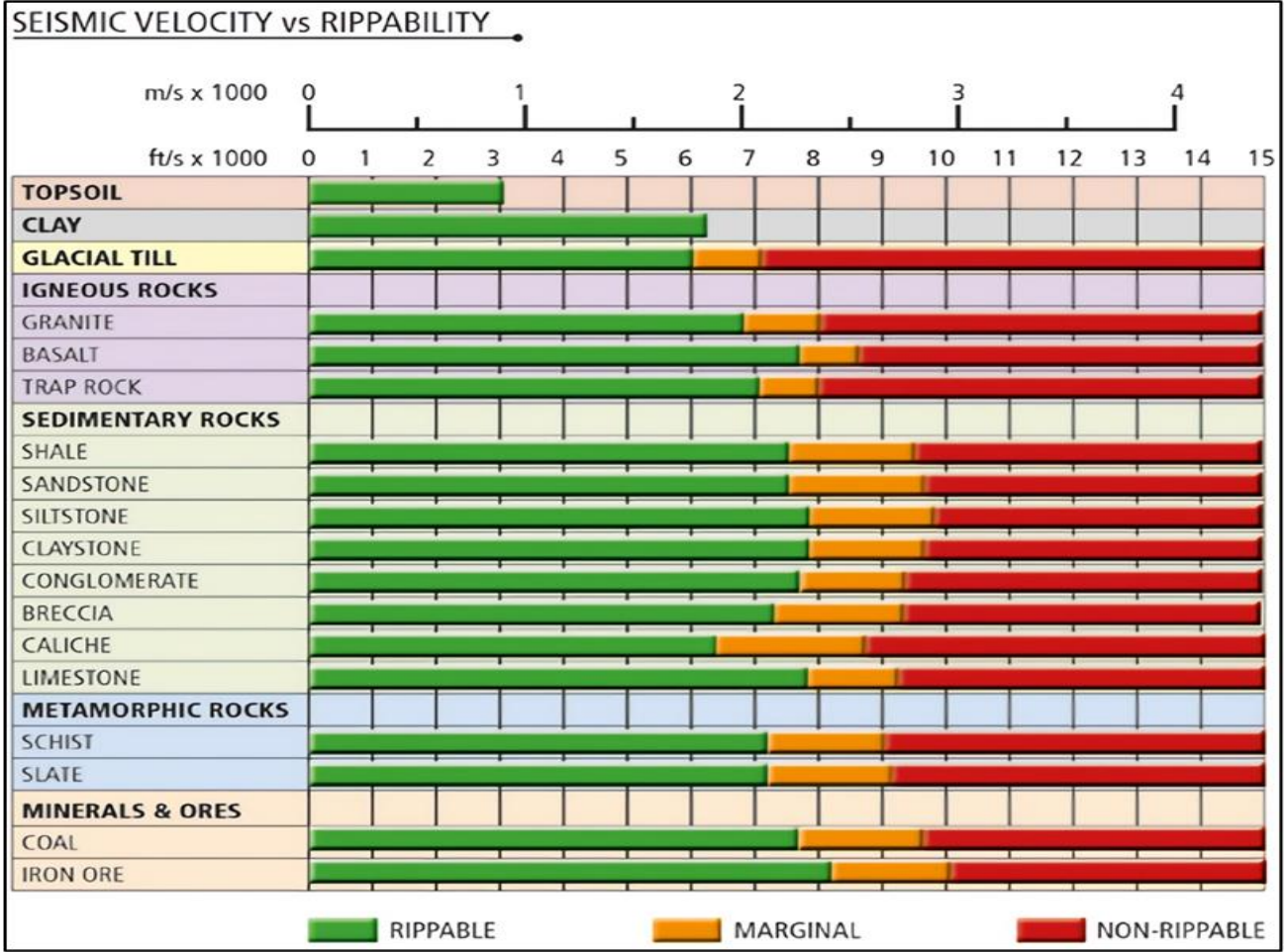

Figure 16 Typical chart of ripper performances related to seismic P-wave velocities (Reynolds 2011) 


\section{$\mathrm{N}$-value}

Several relationships were established between the primary wave velocity and $\mathrm{N}$ value. In this study, the empirical equation stated by Bery and Saad [28] is used for $\mathrm{N}$ value estimation as follows:

$V P=23.605 N-160.43$

Bery and Saad [28] correlated between the $\mathrm{N}$-value of the soil, its type, and the internal friction angle (the force which resists the motion between the particles making up solid materials while undergoing deformation for cohesionless soils). Their classification is listed in Table (2).
The $\mathrm{N}$-value ranges from 46 to 60 in the first layer. The lateral distribution of $\mathrm{N}$-values shows that the northern parts reflect dense soil properties, while the southern parts are classified as very dense which reflects very dense soil properties with an internal angle of friction ranging from 410 - 45․ For the second layer, the $\mathrm{N}$-value ranges from 60 to 73 which reflects very dense soil properties all over the layer which reflect very dense soil properties.

Table 2 Correlation between the $\mathrm{N}$-values, the soil type, and the internal friction angle Bery and Saad [28]

\begin{tabular}{|c|c|c|c|c|c|}
\hline State & Very Loose & Loose & Medium & Dense & Very dense \\
\hline $\mathrm{N}$ value & $0-4$ & $4-10$ & $10-30$ & $30-50$ & over 50 \\
\hline Friction angle & $250-28$ o & $29 \circ-30$ o & $33 \circ-35$ o & 36 - 40ㅇ & 41 - 45ㅇ \\
\hline & & & & & \\
\hline
\end{tabular}
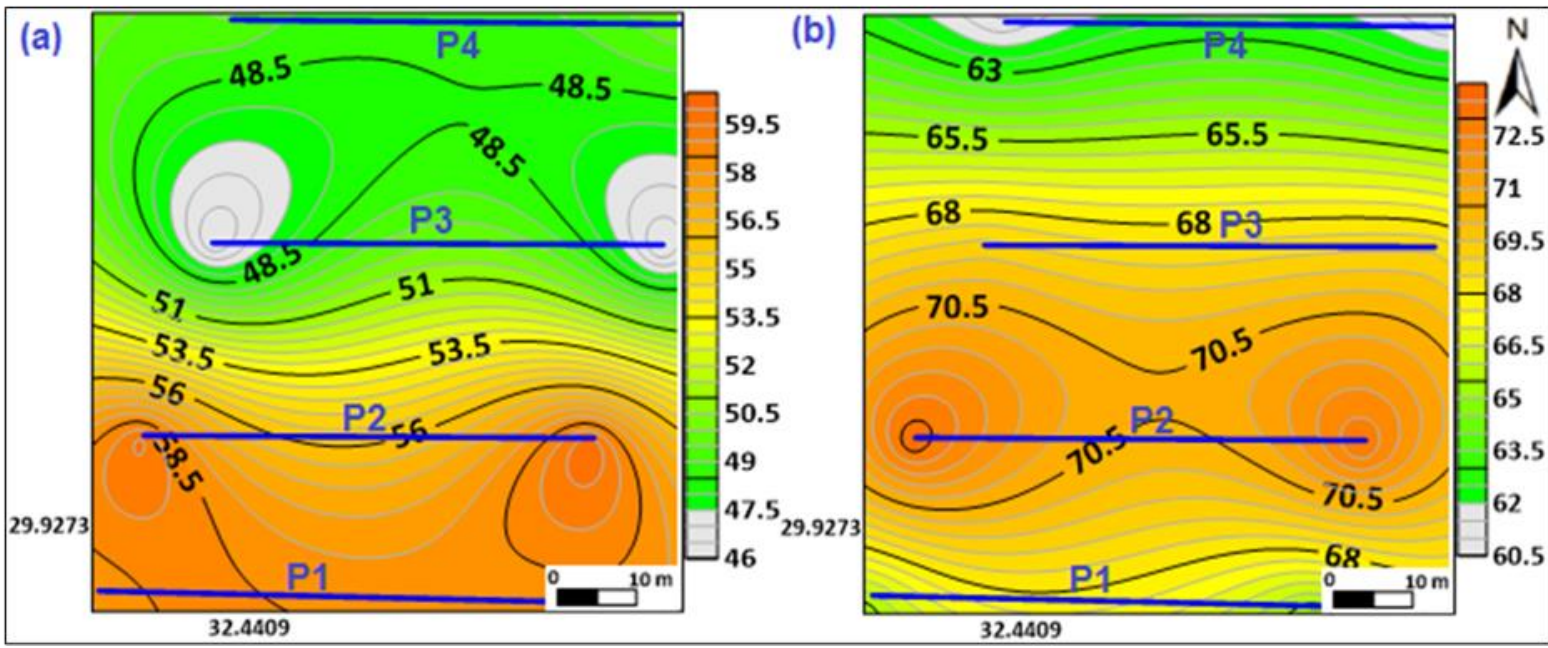

Figure $17 \mathrm{~N}$-value contour map of (A) the first layer and (B) the second layer

\section{Rock Quality Designation (RQD) Index}

Bery and Saad [28] found a relationship between Pwave velocity and RQD:

$V P=21.951(R Q D)+0.1368$

Deere and Deere [29] defined the rocks based on the values of the rock-quality designation (RQD) as listed in Table (3). The rock-quality designation values in the first layer range from $42 \%$ to $55 \%$ which is classified as poor to fair rock quality. While the second layer is classified as fair rock quality as the (RQD) ranges from $58 \%$ to $72 \%$. This reflects the presence of fair rocks.

\section{Foundation Bearing Capacities}

Bearing capacity is the ability of the subsurface materials to hold all the forces from the engineering structures above the ground without experiencing shear
Table 3 Rock quality Description based on the rock-quality designation values Deere and Deere [29].

\begin{tabular}{|c|c|}
\hline RQD & Description \\
\hline $0-25 \%$ & Very poor \\
\hline $25-50 \%$ & Poor \\
\hline $50-75 \%$ & Fair \\
\hline $75-90 \%$ & Good \\
\hline $90-100 \%$ & Excellent \\
\hline
\end{tabular}

failure liquefaction, or excessive settlement. Therefore, the bearing capacity of a subsurface material is defined as the critical load per unit area at either the surface of the ground or at a specific depth below the ground surface 
Keçeli [30]. The ultimate bearing capacity can be estimated by knowing the values of the secondary velocity and the density using the equation stated by Keçeli [30]

$$
\text { Qult }=(\rho * V S) / 100
$$

The first layer demonstrates ultimate bearing capacities ranging from 9.3 to $13.8 \mathrm{~kg} / \mathrm{cm}^{2}$ and the second layer exhibits ultimate bearing capacities ranging from $12.8 \mathrm{~kg} / \mathrm{cm}^{2}$ to $16.8 \mathrm{~kg} / \mathrm{cm}^{2}$.

The allowable bearing capacity (Qall) can be defined as the maximum load to be considered to avoid shear failure or sand liquefaction and is defined by dividing the ultimate capacity by a factor of safety as follows Parry [31]:

$$
\text { Qa }=\text { Qult / F }
$$

We choose a factor of safety equals (5) in this study which makes the allowable bearing capacity for the first layer ranges between 1.8 and $2.7 \mathrm{Kg} / \mathrm{cm}^{2}$. While in the second layer ranges between 2.5 and $3.3 \mathrm{Kg} / \mathrm{cm}^{2}$. These values reflect that the study area is suitable for erecting the proposed structures.

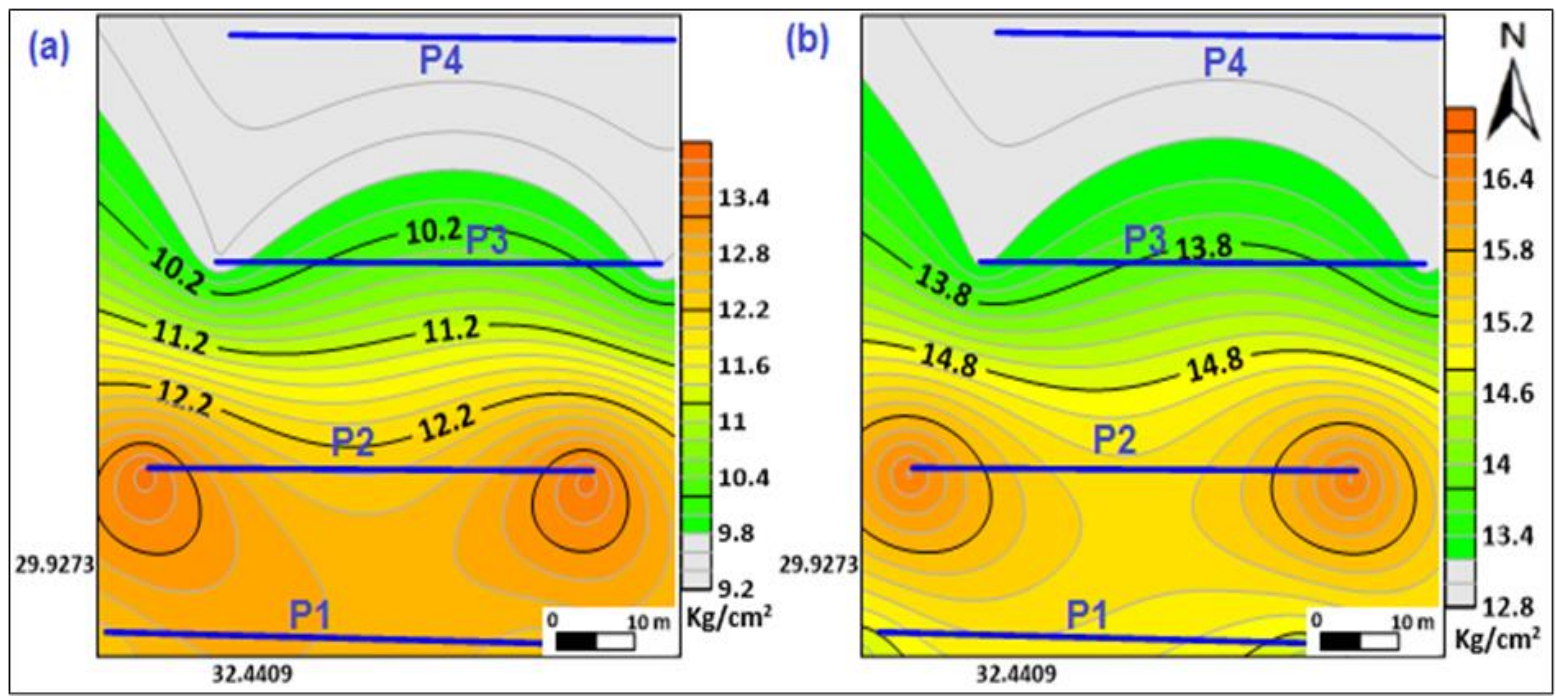

Figure 18 Ultimate bearing capacity contour map of (a) the first layer and (b) the second layer

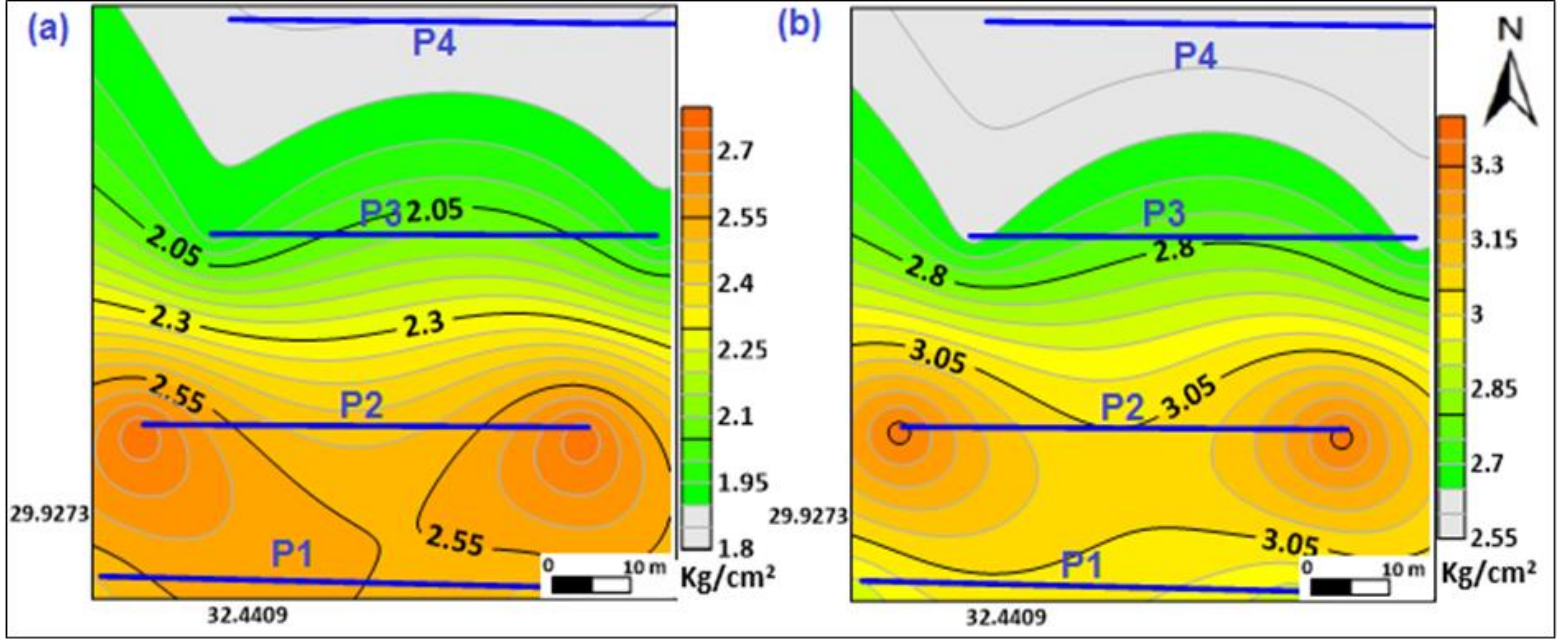

Figure 19 Allowable bearing capacity contour map of (a) the first layer and (b) the second layer. 
Table 4 Seismic velocities for both layers and the corresponding calculated parameters

\begin{tabular}{|c|c|c|c|c|c|c|c|c|c|c|c|c|c|c|c|}
\hline & & $\begin{array}{c}\mathbf{V}_{\mathbf{P}} \\
\mathrm{m} / \mathrm{s}\end{array}$ & $\begin{array}{l}\mathbf{V}_{\mathbf{s}} \\
\mathrm{m} / \mathrm{s}\end{array}$ & $\begin{array}{c}\rho \\
\mathrm{gm} / \mathrm{cc}\end{array}$ & $\begin{array}{l}\phi \\
\%\end{array}$ & $\begin{array}{l}\text { UCS } \\
\mathrm{MPa}\end{array}$ & $\begin{array}{l}\text { UTS } \\
\mathrm{MPa}\end{array}$ & $\sigma^{\prime}$ & $\begin{array}{c}\boldsymbol{\mu} \\
\mathrm{GPa}\end{array}$ & $\begin{array}{c}\mathbf{E} \\
\mathrm{GPa}\end{array}$ & $\begin{array}{c}\mathbf{K} \\
\mathrm{GPa}\end{array}$ & $\mathbf{N}$ & $\begin{array}{c}\text { RQD } \\
\%\end{array}$ & $\begin{array}{c}\text { Qult }_{\text {ul }} \\
\mathrm{Kg} / \mathrm{C} \\
\mathrm{m}^{2}\end{array}$ & $\begin{array}{c}\mathbf{Q}_{\text {all }} \\
\mathrm{Kg} / \mathrm{C} \\
\mathrm{m}^{2}\end{array}$ \\
\hline \multirow{4}{*}{$\begin{array}{l}\text { First } \\
\text { Layer }\end{array}$} & P1 & 1208 & 678 & 1.83 & 32 & 16.0 & 1.3 & 0.27 & 0.84 & 2.13 & 1.6 & 58 & 55 & 12.4 & 2.5 \\
\hline & $\mathrm{P} 2$ & 1247 & 745 & 1.84 & 31 & 16.6 & 1.4 & 0.22 & 1.02 & 2.50 & 1.5 & 60 & 57 & 13.7 & 2.7 \\
\hline & P3 & 924 & 562 & 1.71 & 36 & 11.6 & 1.0 & 0.20 & 0.54 & 1.30 & 0.7 & 46 & 42 & 9.6 & 1.9 \\
\hline & P4 & 1010 & 530 & 1.75 & 35 & 12.9 & 1.1 & 0.31 & 0.49 & 1.29 & 1.1 & 50 & 46 & 9.3 & 1.9 \\
\hline \multirow{4}{*}{$\begin{array}{c}\text { Second } \\
\text { Layer }\end{array}$} & P1 & 1379 & 769 & 1.89 & 29 & 18.7 & 1.5 & 0.27 & 1.12 & 2.85 & 2.1 & 65 & 63 & 14.5 & 2.9 \\
\hline & P2 & 1573 & 853 & 1.95 & 27 & 21.8 & 1.8 & 0.29 & 1.42 & 3.67 & 2.9 & 73 & 72 & 16.7 & 3.3 \\
\hline & P3 & 1473 & 684 & 1.92 & 28 & 20.2 & 1.6 & 0.36 & 0.90 & 2.45 & 3.0 & 69 & 67 & 13.1 & 2.6 \\
\hline & P4 & 1277 & 693 & 1.85 & 31 & 17.1 & 1.4 & 0.29 & 0.89 & 2.30 & 1.8 & 61 & 58 & 12.8 & 2.6 \\
\hline
\end{tabular}

\section{Conclusions and Recommendations}

The results data processing and interpretation show that the subsurface is composed of two layers to the depth of $18 \mathrm{~m}$. The first layer has $\mathrm{P}$-wave velocity ranging from 924 to $1247 \mathrm{~m} / \mathrm{s}$ and S-wave velocity ranging from 530 to $745 \mathrm{~m} / \mathrm{s}$ with thickness ranging between 1 to $4 \mathrm{~m}$ which is corresponding to a layer of crushed dolomitic limestone with calcareous fine materials as obtained from the site investigation. The second layer demonstrates P-wave velocity ranging between 1277 and $1570 \mathrm{~m} / \mathrm{s}$ while the Swave velocity ranges from 693 to $853 \mathrm{~m} / \mathrm{s}$ which is corresponding to a layer composed of coarse to fine aggregates of dolomitic limestone as observed from site investigation. Based on calculated physical, mechanical, elastic and geotechnical properties (Table.4) of both layers at area under investigation are suitable for establishing moderate weight structures.

\section{Conflicts of interest}

"There are no conflicts to declare".

\section{References}

[1] Khandelwal, M. (2013) Correlating P-wave Velocity with the Physico-Mechanical Properties of Different Rocks. Pure Appl Geophys 170:507-514. https://doi.org/10.1007/s00024-012-0556-7

[2] Gaviglio, P. (1989) Longitudinal waves propagation in a limestone: The relationship between velocity and density. Rock Mech Rock Eng 22:299-306. https://doi.org/10.1007/BF01262285

[3] Boadu, F.K. (2000) Predicting the transport properties of fractured rocks from seismic information: Numerical experiments. J Appl Geophys 44:103-113. https://doi.org/10.1016/S0926-9851(99)00020-8

[4] Khandelwal, M. and Ranjith, P.G. (2010). Correlating index properties of rocks with $\mathrm{P}$-wave measurements. Journal of Applied Geophysics, 71(1), 1-5.

[5] Mesbah, M.A., Salama, A.M., Albarqawy, M.A. and Ali, E.M. (2020) Estimation of Geodynamic Properties using Seismic Techniques at a Steel Rolling Factory, Northwestern Gulf of Suez, Egypt. Int J Recent Technol
Eng

8:1785-1794.

https://doi.org/10.35940/ijrte.F7126.038620

[6] Sadek, H. (1926) The geography and geology of the district between Gebel Ataqa and El Galala El Bahariya (Gulf of Suez) Geol. Survey Egypt Paper vol 40, 120 pp

[7] Said, R. (1962) The Geology of Egypt, Rotterdam Pup.Co,The Netherlands.

[8] EGSMA (The Egyptian Geological Survey and Mining Authority). (1999) Geotechnical study and searching of ground water for the industrial area northwestern of the Gulf of Suez, Egypt. Northern and Southern areas Internal report (in Arabic).

[9] Araffa S.A., Saleh, S.H, Abed, M.A. (2020) Application of magnetic and resistivity for groundwater investigations at North Al Ain Sokhona - Cairo Road, Al Ain Sokhna, Egypt. NRIAG J Astron Geophys 9:280-288. https://doi.org/10.1080/20909977.2020.1746894

[10] Conoco, C. (1987) Geological map of Egypt, scale 1: 500,000-NF 36 NE-Bernice, Egypt. Cairo: The Egyptian General Petroleum Corporation.

[11] Snousy, M.G, Zawrah, M.F, Abdel-Moghny, Th. Ebiad, M.A., Rashad, A.M., Khalil, M.M., Abu El Ella, E.M., El-Sayed, E. and Tantawy, M.A. (2017) Mobility and fate of pollutants in the awquifer system of the Northestern Suez Gulf, Egypt. In: Reviews of Environmental Contamination and Toxicology. pp 169-195

[12] Al-barqawy, M.A. (2019) Geotechnical report for the possibility of the area for construction purposes at ELCO Steel Rolling Factory, Ataqa Industrial Area, Suez., unpublished report

[13] Wittig, K., Ryberg, T. and Weber, M.H. (2017) New insights into the seismic time term method for heterogeneous upper mantle slowness structures. GEM Int J Geomathematics 8:43-56. https://doi.org/10.1007/s13137-016-0090-3

[14] Geometrics, OYO (2009) SeisImager Manual

[15] Park C.B., Miller, R.D., Xia, J. and Ivanov, J.M. (1999) Multichannel analysis of surface waves. Lead Edge 18:1392-1396. https://doi.org/10.1190/1.1438226

[16] Park C.B., Miller, R.D., Xia, J. and Survey, K.G. (1998) Imaging dispersion curves of surface waves on 
multi-channel record. SEG Tech. Progr. Expand. Abstr. 1998. Soc. Explor. Geophys. 1380-1377

[17] Bowles, J.E. (1982) Foundation Analysis and Design. Eng Geol 20:587. https://doi.org/10.1016/00137952(84)90010-3

[18] Gardner, G.H., Gardner, L.W. and Gregory, A.R. (1974) Formation velocity and density-the diagnostic basics for stratigraphic traps. GEOPHYSICS 39:770-780. https://doi.org/10.1190/1.1440465

[19] Wyllie, M.R., Gregory, A.R. and Gardner, G.H. (1958) An experimental investigation of factors affecting elastic wave velocities in porous media. GEOPHYSICS 23:459-493. https://doi.org/10.1190/1.1438493

[20] Watkins, J.S., Walters, L.A. and Godson, R.H. (1972) Dependence of in-situ compressional-wave velocity on porosity in unsaturated rocks. GEOPHYSICS 37:29-35. https://doi.org/10.1190/1.1440249

[21] Altindag, R. (2012) Correlation between P-wave velocity and some mechanical properties for sedimentary rocks. J South African Inst Min Metall 112:229-237

[22] Saad, A.M., Shebl, S., Elsamei, S.A. and Hamed, D. (2013) Application of Shallow Seismic Refraction To Detect Engineering Problems, Madinaty City, Egypt. Curr Sci Int 2:15-29

[23] Sjögren, B. (1984) Shallow Refraction Seismics. Springer Netherlands, Dordrecht

[24] Toksöz, M.N., Cheng, C.H. and Timur, A. (1976) Velocities of seismic waves in porous rocks. GEOPHYSICS 41:621-645. https://doi.org/10.1190/1.1440639
[25] Lowrie, W. (2007) Fundamentals of Geophysics. Cambridge University Press, Cambridge

[26] Reynolds (2011) An Introduction to Applied and Environmental Geophysics 2nd Edition, second. Cambridge University Press

[27] MacGregor, F., Fell, R., Mostyn, G. R., Hocking, G., and McNally, G. (1994). The estimation of rock rippability. Quarterly Journal of Engineering Geology and Hydrogeology, 27(2), 123-144.

[28] Bery, A.A. and Saad, R. (2012) Correlation of Seismic P-Wave Velocities with Engineering Parameters (N Value and Rock Quality) for Tropical Environmental Study. Int J Geosci 03:749-757. https://doi.org/10.4236/ijg.2012.34075

[29] Deere, D.U. and Deere, D.W. (1988) The Rock Quality Designation (RQD) Index in Practice. In: Rock Classification Systems for Engineering Purposes. ASTM International, 100 Barr Harbor Drive, PO Box C700, West Conshohocken, PA 19428-2959, pp 91-91-11

[30] Keçeli, A. (2012) Soil parameters which can be determined with seismic velocities. Jeofizik 17-29. https://doi.org/11.a02/jeofizik-1011-31

[31] Parry, R.H. (1977) Estimating Bearing Capacity in Sand from SPT Values. J Geotech Eng 6:1-21 